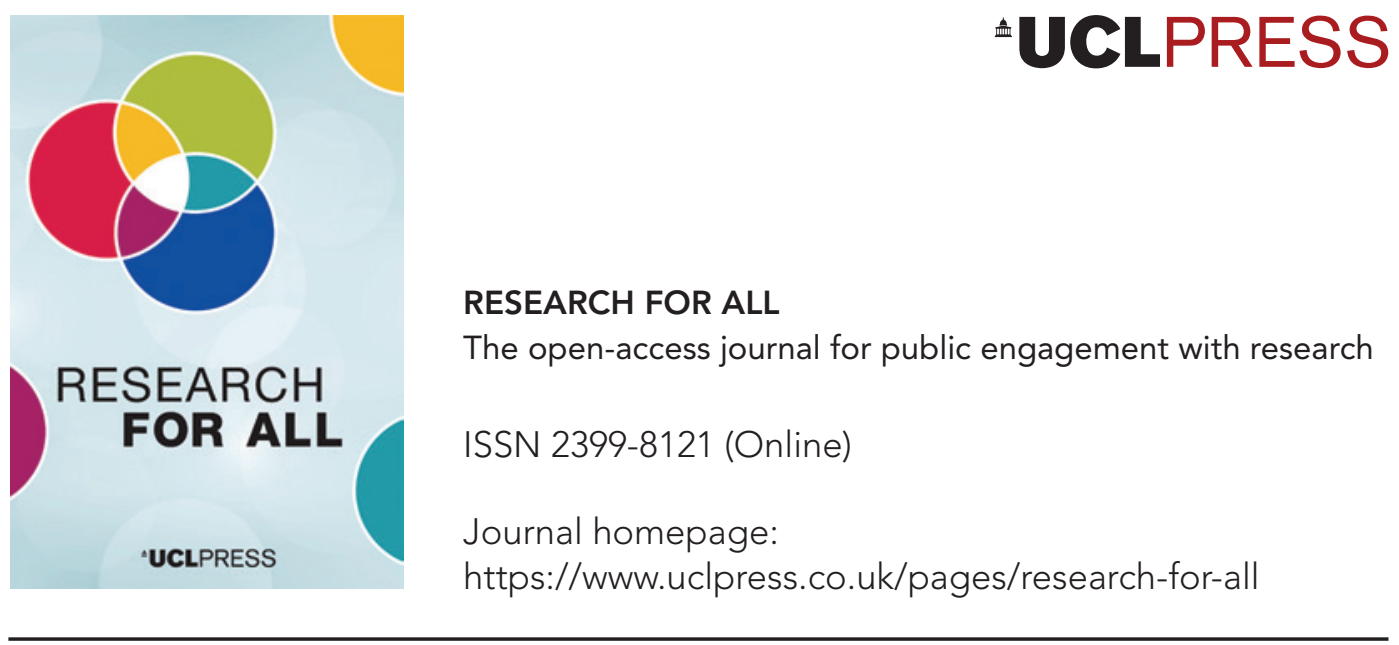

\title{
Editorial: Engagement in a time of great change
}

\section{Sophie Duncan (iD and Sandy Oliver (iD}

\section{How to cite this article}

Duncan, S. and Oliver, S. (2020) 'Editorial: Engagement in a time of great change'. Research for All, 4 (2), 145-9. Online. https://doi.org/10.14324/RFA.04.2.01

Publication date: 22 September 2020

\section{Copyright}

(C) 2020 Duncan and Oliver. This is an open-access article distributed under the terms of the Creative Commons Attribution Licence (CC BY) 4.0 https://creativecommons.org/licenses/ by/4.0/, which permits unrestricted use, distribution and reproduction in any medium, provided the original author and source are credited.

\section{Open access}

Research for All is a peer-reviewed open-access journal. 


\title{
Editorial: Engagement in a time of great change
}

\author{
Sophie Duncan* - National Co-ordinating Centre for Public Engagement, UK \\ Sandy Oliver* - UCL Institute of Education, UK
}

It is June 2020, and, as we write this editorial, the world is caught up in a global pandemic, the scale of which is unprecedented in modern times. Not only has COVID-19 caused huge numbers of deaths, but the associated measures to contain the virus have seen many countries undergo lockdown of their economies and social worlds. What is clear is that both COVID-19 and the associated lockdown threaten human life, education, the economy, the public sector, government spending, livelihoods and well-being, and the impacts will be with us for many years to come.

It seems to us that now, as in the past, engagement is really important, as the robustness of the foundations we have been building are tested by such rapid and far-reaching changes. Public engagement has animated researchers who have sought to share their knowledge and expertise with policymakers and the wider public, all of whom need to make decisions about how to live. We have seen researchers across the world unite to share knowledge, insights and approaches to understanding and halting the spread of the virus, and to treating those who have contracted it. We have seen front-line and key workers providing support infrastructure - health care, food, waste disposal, communications - enabling others to remain at home and reduce the spread of the virus. Families, carers and volunteers have come together to support the most vulnerable people in our society, protecting them from exposure to the virus, and ensuring they have all they need, while governments struggle to address these challenges at a national level. And we have found ways to unite: creating online choirs and orchestras, clapping for carers and other key workers on the doorsteps of our homes, and creating meaningful socially distant community engagement and participation.

COVID-19 is a challenge that we are facing collectively. It is a virus that respects no borders, that has no cure, and that no one can tackle alone. As a consequence, we need to bring in expertise, understanding and skills from publics, policymakers, researchers, medics, care-home workers, charities and businesses. Indeed, we need to work together to make sense of what to do now, and how to navigate many potential futures.

The global pandemic has shone a light on social inequalities. It has highlighted the increasing number of people who are struggling to make ends meet, the digital divide in terms of who has access to online communications and communities, and that for many communities across the world, social distancing is not an option. In the UK, it has raised awareness of our reliance on migrant workers to keep core services going in our care homes, the NHS, our hospitality industries, and in the farming and food industry. It has forced us to confront inequalities regarding race, with black and minority ethnic (BME) individuals being more vulnerable to the virus and its deadly effects. We are being forced to imagine new ways of being a society, and to consider our collective responsibilities to build differently in the future, all while experiencing a very challenging context. 
The global pandemic is also showing us how we can work differently. It exemplifies how human activity has affected the planet, and the changes that can be brought about by collective behaviour change. With Greta Thunberg's words ringing in our ears, we dare to imagine that our lives could be lived more in harmony with the earth's resources in the future.

Against this backdrop, we are all struggling to make sense of the now and the what next. One ray of hope for us all lies in engagement - engagement that seeks to support us to work across difference, to collaborate for change, to open up knowledge for the participation of all. Research is making a real contribution to the global efforts to halt the virus; it will also be an important part of reimaging our futures. So, engagement - from inspiring and informing people, to collaborating on research projects together - can make a huge contribution.

Organizations that fund, conduct, support or use research are all reshaping their priorities, not only towards COVID-19, but also in terms of how they work with others to achieve their aims. This energy for new collaborations builds on a long tradition, as seen in papers published in Research for All. The papers in this issue sing of the value and importance of collaboration. Barke and colleagues reflect on their experiences of co-production from the point of view of research associates. They remind us of the importance of having clear understanding of the aims of the project and ways of working, and the importance of taking time to nurture relationships and build trust. They also reflect on the need to 'hold' a space for co-production, a responsibility that tended to rest with them as research associates. While this was an important role, it was challenging, and they were often the only ones who had time to work alongside all the different participants and help make the programme work. Goldstraw et al. also reflect on co-production, and on using artistic approaches to build social cohesion. This article represents the views of the artists involved in the project. They emphasize the importance of arts as process as well as product, bringing to mind the analogy with engaged research, which is as much process as output. Both Barke et al. and Goldstraw et al. reflect on the importance of understanding arts-based practice, and ensuring that it realizes its potential for supporting equitable knowledge processes.

Williams highlights the idea that engaged research is a valuable process as well as a valuable outcome in the Talking Together pilot project - which saw pairs of autistic and non-autistic strangers brought together to have conversations about loneliness. The output was some rich qualitative data about loneliness and how it could be tackled, but the process tackled the impact of loneliness on the participants, in what the author calls 'an act of radical world building' (p.314).

Eisenstadt and McLellan reflect on a five-year co-production research programme focused on historical mapping. They remind us that one of the purposes of communities and universities working together is to bring in different perspectives. Therefore, when building relationships characterized by difference, it is important to foreground the co-production - practically, epistemologically and affectively.

The Black Lives Matter campaign, which sees us stand together against racism in all its forms, and that saw millions of people worldwide take to the streets in protest, recognizes that the very structures of our society need to be changed. In the UK, we look to our universities, where there are disproportionally low numbers of BME staff, researchers, senior leaders and students. A recent Wellcome report also highlighted the endemic culture of bullying and harassment that sits at the heart of many researchers' experiences of academic life (Wellcome and Shift Learning, 2020). It is clear that change is needed. The Common Cause programme highlighted some 
key enablers that could transform how BME communities participate in research, and bring much-needed insights and expertise into knowledge building and sharing (Bryan et al., 2018). They highlight ten key principles that underpin effective engagement between universities and BME communities. Bruton et al., who specifically considered the barriers and facilitators for the participation of BME communities in health research, reflect these ideas. They drew on intersectionality to help inform their sense-making, recognizing the many identities we have, and the diversity of communities, however defined. They conclude that the issues lie in the engagers, and that we cannot assume people will trust researchers or the research, and that this takes time to build. They highlight that working alongside trusted community leaders can help researchers work in appropriate ways to address the concerns and constraints of those they seek to engage. They also remind us of the critical importance of diverse perspectives on health research, ensuring that the outcomes are relevant to all.

Collaborative processes can also involve other sectors. Clough and Adams provide the specific example of 'Evidence Cafés', a methodology to support police forces across the UK to work with academics to improve practice. Their three case studies illustrate the key enablers that lead to equitable knowledge exchange. Baker and colleagues consider the importance of researchers and industry working together, both to co-produce research and also to co-disseminate it. Their work to build a more resilient water sector in the UK benefited from the sustained funding offered by the lead author's career fellowship, which offered five years' funding to the programme: a timely reminder that short-term funding cycles do little to support co-production.

Encouraging participation was also the focus of Berry and D'Alessandro, who wanted to attract researchers, patients and publics to get involved in health research. With limited time and resources, they worked with existing networks and created the solution in partnership with those they sought to engage, leading to the campaign Research, \#Huh, comprising a website and social media campaign.

While we celebrate all the great work that is happening on co-production, it is important to recognize the many forms that engagement can take, and how these also have huge value. Joanna Verran shares her journey into public engagement, in 'What inspired my thinking?'. She reminds us that all engagement requires good listening, whether you are running the Bad Bugs Book Club (an innovative programme she set up ten years ago) or participating in a science festival.

So, with so many people involved in engagement, how can we ensure that they bring their diverse knowledges and experiences to bear in delivering effective approaches? Seakins and Fitzsimmons share their experiences of running a professional development academy for all those involved in engagement within their institution - and how this led to building capacity and confidence. Another co-production research module was trialled by Hally and colleagues. The reflections of all those involved are captured, recognizing that for many, co-producing research is a new and novel experience that brings up unique feelings that can take time to surface. Therefore, creating a space for reflection is a key part of enabling the collaborations to flourish. In addition, investing in engagement needs to be complemented by recording the results of this investment. Brady and Preston ask when and where children have been involved in health research, and how that impacted on the research. They see a need for better systems to help us collate learning at a country level.

In reading the wealth of papers for this issue, we repeatedly read words that begin with the two letters 'co': co-production, collaboration, communication, community, 
contact, confirming, co-disseminating, co-making, co-creating. These words lie at the heart of work that sees us value our difference, and find ways to imagine new futures. It helps lay the foundations for a pathway to hope; a hope that is shared by all.

\section{Articles in this issue}

Baker, K., Ward, S., Turner, B., Webber, J., Sweetapple, C., Drake, P., Thomas, D., Melville-Shreeve, P., Fu, G., Cherington-Rimmell, S., Farmani, R. and Butler, D. (2020) 'Co-producing research with academics and industry to create a more resilient UK water sector'. Research for All, 4 (2), 150-68. Online. https://doi.org/10.14324/RFA.04.2.02

Barke, J., Thomas-Hughes, H. and Howard, M. (2020) 'Reflections from the field: Researchers' experiences of co-production'. Research for All, 4 (2), 169-79. Online. https://doi.org/10.14324/ RFA.04.2.03

Berry, E. and D'Alessandro, M. (2020) 'Research, \#Huh? Improving research awareness in NHS Grampian through a website and more'. Research for All, 4 (2), 180-93. Online. https://doi.org/10.14324/RFA.04.2.04

Brady, L.-M. and Preston, J. (2020) 'How do we know what works? Evaluating data on the extent and impact of young people's involvement in English health research'. Research for All, 4 (2), 194-206. Online. https://doi.org/10.14324/RFA.04.2.05

Bruton, J., Jones, K., Jenkins, R.H., Davies, B., Ward, H. and Toledano, M.B. (2020) 'Enabling participation of Black and Minority Ethnic (BME) and seldom-heard communities in health research: A case study from the SCAMP adolescent cohort study'. Research for All, 4 (2), 207-19. Online. https://doi.org/10.14324/RFA.04.2.06

Clough, G. and Adams, A. (2020) 'Evidence Cafés: Overcoming conflicting motivations and timings'. Research for All, 4 (2), 220-41. Online. https://doi.org/10.14324/RFA.04.2.07

Eisenstadt, N. and McLellan, J. (2020) 'Foregrounding co-production: Building research relationships in university-community collaborative research'. Research for All, 4 (2), 242-56. Online. https://doi.org/10.14324/RFA.04.2.08

Goldstraw, K., McMillan, A., Mort, H., Pahl, K., Pool, S., Rafiq, Z. and Rasool, Z. (2020) 'Co-producing artistic approaches to social cohesion'. Research for All, 4 (2), 257-75. Online. https://doi.org/10.14324/RFA.04.2.09

Hally, R., Murphy, A., O'Connell, J., Robinson, S., Pyrz, K., Burns, K. and O'Mahony, C. (2020) 'Participating in a community-based participatory research module: A reflective inquiry'. Research for All, 4 (2), 276-90. Online. https://doi.org/10.14324/RFA.04.2.10

Seakins, A. and Fitzsimmons, A. (2020) 'Mind the gap: Can a professional development programme build a university's public engagement community?' Research for All, 4 (2), 291-309. Online. https://doi.org/10.14324/RFA.04.2.11

Verran, J. (2020) 'Who inspired my thinking? - The co-factor: conversation, collaboration, co-production'. Research for All, 4 (2), 310-13. Online. https://doi.org/10.14324/RFA.04.2.12

Williams, G.L. (2020) 'From anonymous subject to engaged stakeholder: Enriching participant experience in autistic-language-use research'. Research for All, 4 (2), 314-28. Online. https://doi.org/10.14324/RFA.04.2.13

\section{Acknowledgements}

Research for All is a collaborative project that relies on a range of associate editors with experience of engaged research in a variety of contexts. The associate editors who advised us on the content for this issue of the journal are:

- Cath Chamberlain - Baker IDI Heart and Diabetes Institute, Australia

- Ceri Davies - University of Brighton, UK

- Helen Featherstone - University of Bath, UK

- Lou Harvey - University of Leeds, UK

- Natalia Kucirkova - University of Stavanger, Norway, and UCL Institute of Education, UK

- Sarah Lloyd - University of Hertfordshire, UK

- Paul Manners - National Co-ordinating Centre for Public Engagement, UK 
- Henk Mulder - University of Groningen, The Netherlands

- Kate Pahl - Manchester Metropolitan University, UK

- Anne Rathbone - BoingBoing, UK

- Ruth Stewart - University of Johannesburg, South Africa

- Crystal Tremblay - University of Victoria, Canada.

We extend our thanks to them and to all the expert reviewers - two for each contribution - who helped us guide authors towards their final drafts.

\section{References}

Bryan, D., Dunleavy, K., Facer, K., Forsdick, C., Khan, O., Malek, M., Salt, K. and Warren, K. (2018) Common Cause Research: Building research collaborations between universities and Black and Minority Ethnic communities. University of Bristol and the Arts and Humanities Research Council Connected Communities Programme. Online. https://cpb-eu-w2.wpmucdn.com/blogs.bristol. ac.uk/dist/a/358/files/2018/09/CC_Enablers_Barriers_final_sp-2c2f4bh.pdf (accessed 22 June 2020).

Wellcome and Shift Learning (2020) What Researchers Think About the Culture They Work In. London: Wellcome. Online. https://wellcome.ac.uk/sites/default/files/what-researchers-thinkabout-the-culture-they-work-in.pdf (accessed 22 June 2020). 